\title{
Access to special care dentistry, part 4. Education
}

\author{
A. Dougall ${ }^{1}$ and J. Fiske²
}
IN BRIEF
- Many groups of patients with disabilities have a higher risk of oral disease.
- Understanding how various conditions affect an individual's ability to manage their oral hygiene can make the difference between a person being reliant on a carer and being able to retain at least a degree of independence.
- There are now many opportunities for postgraduate study for dentists to refresh their knowledge and skill base.

\begin{abstract}
Many groups of patients with disabilities have a higher risk of oral disease due to compromised oral hygiene as a consequence of their impairment, oral manifestations of their particular condition and/or the side effects of drug regimes, notably xerostomia and sugar in medicines. This article looks at education related to oral health and its management for both patients and carers. It will encourage a tailored routine for oral hygiene, taking account of the best time of day for the person concerned, the facilities available to them, appropriate preventive measures and the support and adaptations required to minimise the effect their impairment has on managing their oral hygiene. Additionally, it considers educational issues for the dental team related to some elements of managing oral health of people with disability, the dental team's responsibility in educating other health professionals and the availability of undergraduate and postgraduate education in special care dentistry.
\end{abstract}

Many groups of patients with disabilities have a higher risk of oral disease due to compromised oral hygiene as a consequence of their impairment, oral manifestations of their particular condition

\begin{tabular}{l} 
ACCESS TO SPECIAL \\
CARE DENTISTRY \\
\hline 1. Access \\
2. Communication \\
3. Consent \\
4. Education \\
5. Safety \\
6. Special care dentistry services for \\
adolescents and young adults \\
7. Special care dentistry services for \\
middle-aged people. Part 1 \\
8. Special care dentistry services for \\
middle-aged people. Part 2 \\
9. Special care dentistry services for \\
older people
\end{tabular}

'Lecturer and Consultant for Medically Compromised Patients, Division One/Special Care Dentistry, Dublin Dental School and Hospital, Lincoln Place, Dublin 2, Ireland $;{ }^{2^{*}}$ Chairperson of the Specialist Advisory Group in Special Care Dentistry/Senior Lecturer and Consultant in Special Care Dentistry, Department of Sedation and Special Care Dentistry, King's College London Dental Institute, Floor 26, Guy's Tower, London, SE1 9RT ${ }^{*}$ Correspondence to: Dr Janice Fiske

Email: Janice.Fiske@gstt.nhs.uk and/or the side effects of drug regimes, notably xerostomia and sugar in medicines. ${ }^{1}$ This article looks at education related to oral health and its management for both patients and carers. Additionally, it considers educational issues for the dental team related to some elements of managing oral health of people with disability, the dental team's responsibility in educating other health professionals, and the availability of undergraduate and postgraduate education in special care dentistry.

\section{PATIENT EDUCATION}

Educating and motivating patients to carry out effective daily oral hygiene can be challenging but immensely rewarding when efforts are successful. Some people with disability have no problems managing their oral hygiene. Others have difficulty because of lack of cognition to understand and remember what needs to be done, as in some learning disabilities; lack of manual dexterity, as in some physical disabilities; and lack of co-ordination, as in some neurological conditions. Understanding how various conditions affect an individual's ability to manage their oral hygiene and working with them to adapt the tools available for the task can make the difference between a person being reliant on a carer and being able to retain at least a degree of independence.

\section{Dyspraxia}

Developmental dyspraxia is a neurological disorder that affects the way in which the brain processes information, impinging on the planning of what to do and how to do it and resulting in an impairment of the organisation of movement. ${ }^{2}$ It is a common condition that impacts on the ability to carry out effective oral hygiene. Up to $10 \%$ of the population may show symptoms of dyspraxia, with around 2\% being severely affected $^{2-4}$ and with males four times more likely to be affected than females. ${ }^{2}$ It is associated with problems of perception, language and thought and manifests as a motor disorder of the way that the brain processes information in three key areas: ${ }^{3}$

1. Ideation - forming the idea of using a known movement to achieve a planned purpose

2. Motor planning - planning the action needed to achieve this idea

3. Execution - carrying out the planned movement.

Developmental dyspraxia is currently poorly understood by both health professionals and the general community. 


Table 1 The elements of dyspraxia likely to affect carrying out oral hygiene tasks
The elements of dyspraxia likely to affect carrying out oral hygiene tasks include:
- Poor hand-eye co-ordination
- Lack of manual dexterity, particularly with two-handed tasks such as using cutlery,
self-care and grooming, such as fastening clothes and brushing teeth
- Poor manipulative skills, such as difficulty with typing and writing
- Inadequate grasp, causing a poor 'pen grip'
- Difficulty planning and organising thought
- Poor memory, particularly short-term difficulty in following instructions, especially more than
one at a time
- Difficulty with concentration leading to daydreaming, being easily distracted and slow to finish tasks

Increased awareness would allow the needs of families and individuals to be responded to in a more understanding and supportive way. ${ }^{5}$ However, dyspraxia can be difficult to understand as it affects each person in different ways and at different stages of development. Also, the way in which an individual is affected is not consistent. For example, one day they may be able to perform a specific task and on another they may be unable to perform the same task. There can be an overlap with dyslexia and the two conditions often co-exist in the same person. ${ }^{6}$ Dyspraxia can also overlap with conditions such as ADD (attention deficit disorder), ADHD (attention deficit hyperactivity disorder), Asperger's syndrome and dyscalculia (difficulty with mathematical concepts).

People with dyspraxia usually have a combination of problems, including a tendency to fall, trip and bump into things; clumsy gait and movement; and difficulty changing direction and stopping or starting actions. ${ }^{6}$ The elements of dyspraxia likely to affect carrying out oral hygiene tasks are set out in Table 1. ${ }^{2}$ Additionally, some people with dyspraxia have 'tactile defensiveness' and are over-sensitive to touch. They may also be under- or over-sensitive to light, smell, taste, temperature and pain, ${ }^{2}$ all of which can impact on the provision of oral hygiene instruction and dental treatment. Some people have 'articulatory dyspraxia', which causes difficulties with pronunciation and with organising the content and sequence of their language such that they may talk continuously and/or repeat themselves. ${ }^{2}$ Adults with dyspraxia may develop depression, have mental health problems and experience emotional and behavioural difficulties. ${ }^{?}$

Whilst there is no cure, people with dyspraxia can learn ways to get around their difficulties. Management usually involves a team approach using the skills of different specialists according to the specific needs of the individual, such as occupational therapists, speech and language therapists, psychologists and specialist teachers. ${ }^{4}$ All people with dyspraxia can improve their dexterity with encouragement and need help in practising simple tasks followed by step-by-step progress into more complex activities. ${ }^{7}$ This approach can be useful when providing oral hygiene instruction (OHI), provided it is coupled with patience and understanding.

People with dyspraxia have good days and bad days. If the dental visit coincides with a bad day, it can be prudent to postpone doing much in the way of OHI or dental treatment as it is recognised that people with dyspraxia get easily stressed and anxious and tend to opt out of things that they find too difficult. Small steps, positive feedback and encouragement are useful strategies.

\section{Oral hygiene and self-care}

Some disabled people require more than routine oral care to keep their mouth healthy, due to their condition or the treatment for their condition. ${ }^{8}$ The National Institute of Dental and Craniofacial Research sets out the three principle reasons for this as:

- Genetic or systemic disorders that affect oral health

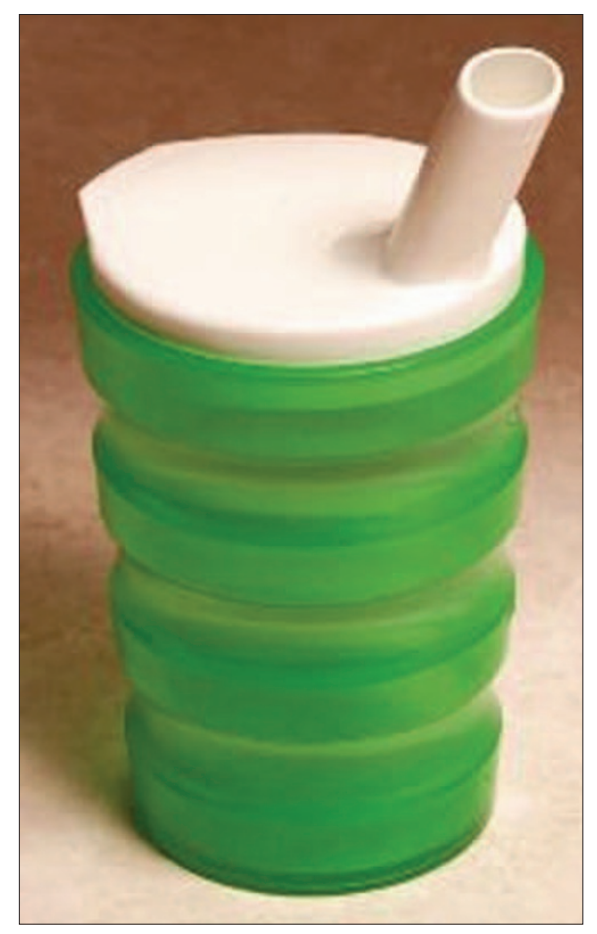

Fig. 1 'No spill' beaker

- Undergoing medical treatments that cause oral problems, and

- Mental or physical disabilities that complicate oral hygiene or dental treatment.

People with disabilities often need extra help to achieve and maintain good oral health. ${ }^{8}$ Although a caregiver may be willing to brush the person's teeth, as much as possible it should be carried out by the individual as this reduces dependency on others who may not necessarily place oral health high on their busy agenda. ${ }^{9}$ In addition, the psychological benefits of self-care result in feelings of higher self-esteem and accomplishment, a situation that is particularly true for people who have physical difficulties and no cognitive problems. ${ }^{9}$

Technical aids and methodical instruction are often required to help people with disability to carry out effective cleaning without assistance. ${ }^{10}$ Making a difference in the oral health of a person with a developmental or physical disability may go slowly at first, but determination can bring positive results and a significant impact on their quality of life. ${ }^{8}$ The first important step is to identify a tailored routine for oral hygiene, taking account of the best time of day for the person concerned, the facilities available to them and the support and 


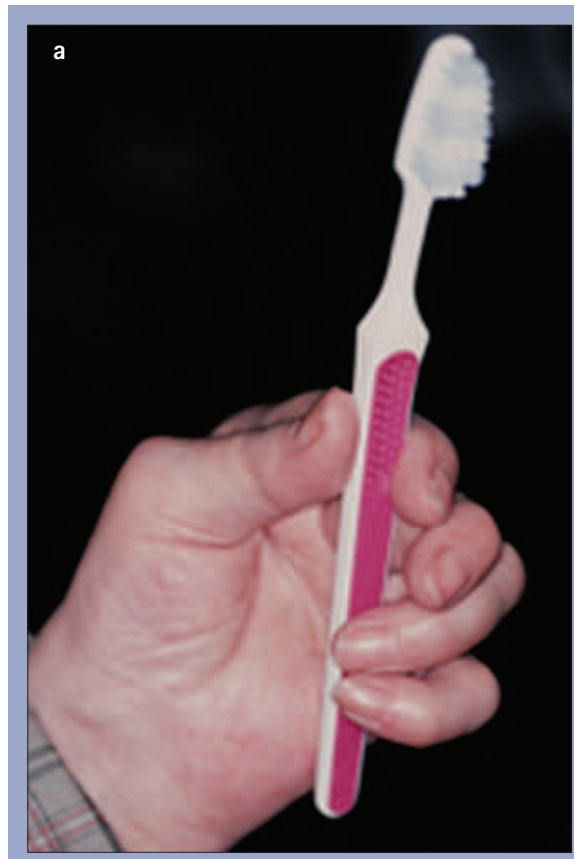

Fig. 2a Dupytren's contracture of the hand

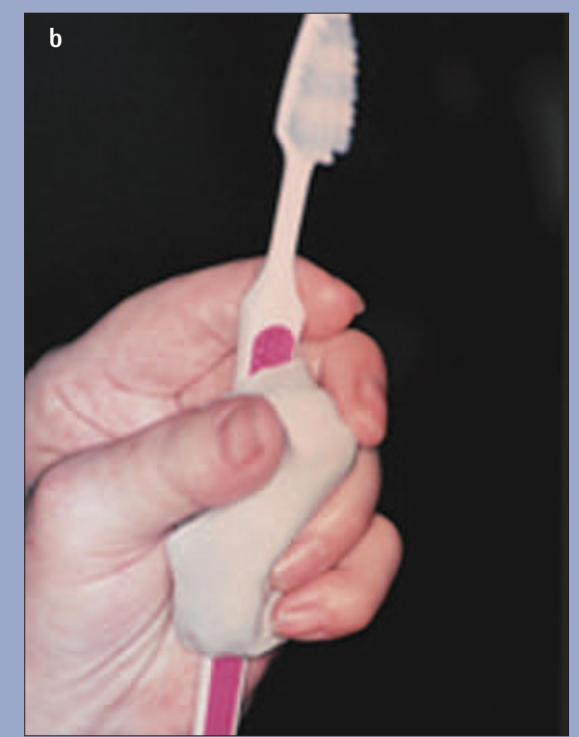

Fig. $2 b$ Silicone putty added to a toothbrush handle to provide an improved grip (reproduced with kind permission of Quintessence Publishing Co., Ltd) adaptations required to minimise the effect their impairment has on managing their oral hygiene. For example, it is essential that the person has the facilities to sit down in front of a wash-basin with a mirror at face height in order to provide a relaxed posture. ${ }^{10}$ Posture is of great importance during tooth-brushing as problems caused by high muscle tone and altered motor ability will reduce control and encourage unwanted movements. Muscle tone increases when a person with muscle spasticity stands during oral hygiene procedures, resulting in stiffer movements, impaired control of balance and diminished powers of concentration. ${ }^{10}$ Some people with high muscle tone or dyspraxia find it difficult to concentrate on, or to co-ordinate, two or more things at the same time, for instance keeping the mouth open and brushing the teeth. The use of a photographic retractor can help the person to keep their mouth open whilst holding the oral musculature and soft tissues away from the teeth, allowing them to concentrate their efforts on brushing. ${ }^{10}$

When it comes to rinsing, people with tremors or movement disorders that preclude them from holding a traditional cup may find a specially adapted 'no spill beaker' (such as those available at the Mun-H-Centre oral assistive devices centre) helpful (Fig. 1). ${ }^{11}$ Another option is to use a bendy straw and beaker held with both hands. It can be used to facilitate both rinsing after toothbrushing or the use of mouthwashes. ${ }^{12}$

\section{Toothbrush adaptations}

The most common tool for effective mechanical control of dental plaque is a toothbrush. The presence of physical and/or cognitive disabilities can create difficulties both in holding and manipulating a toothbrush. ${ }^{13}$ Various toothbrush adaptations are described in the literature to facilitate managing the brush for a diverse range of conditions.

\section{Grasp, manipulation and control}

For patients whose main deterrent to personal self-care is related to grasp, manipulation or control of the brush, adaptations have been devised which include enlarged handles, hand attachments and elongated handles. ${ }^{9}$ The aim of the toothbrush adaptation is to provide a handle with a stable grip, whilst its shape enables the person to feel how to manipulate the brush in the mouth adequately during cleaning. ${ }^{10}$

Grasp - for people who cannot grasp and hold, the objective is to fasten the brush handle to the hand. This can be achieved by using a velcro strap with a pocket on the palm side into which the toothbrush can be inserted., ${ }^{1,9,13}$ This design is readily available on the commercial market but is usually marketed

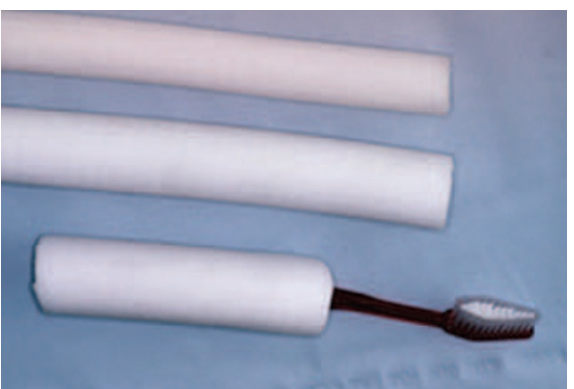

Fig. 3 'Plastazote' tubing, available in different guages, used to broaden a toothbrush handle for easier grip (reproduced with kind permission of Quintessence Publishing Co., Ltd)

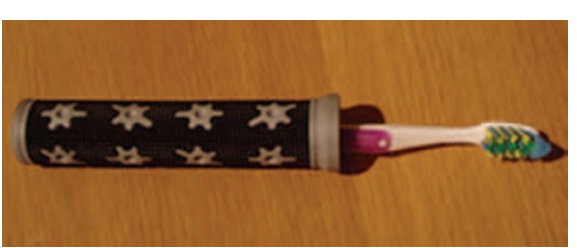

Fig. 4 Toothbrush handle thickened using a bicycle handlebar grip

for the use of cutlery. ${ }^{11}$ A temporary option is to use the handle of a nail brush attached to the toothbrush by water-resistant tape. ${ }^{9}$

Fixed fingers - for a patient with fingers permanently flexed or fixed in a fist, toothbrushes with variation in the grip and handle width in all shapes and sizes are available commercially ${ }^{1}$ and a suitable brush that inserts directly into the patient's grasp can be selected. ${ }^{9}$ The handle of some brushes can be modified by immersion in hot water, a useful feature when the angle of the head to handle needs to be modified to make brushing possible. ${ }^{1}$

Limited hand closure or reduced manual dexterity - here, the objective is to enlarge the diameter of the brush handle to fit the hand. The simplest method of improving the grip involves inserting the brush handle into another material to improve its size, shape or surface characteristics. ${ }^{13}$ Plastazote tubing and silicone putty are among the simplest and most successful techniques. ${ }^{13}$ Silicone putty ${ }^{14}$ moulded to the brush handle and hand grip has been successful for people with conditions such as Dupytren's contracture and rheumatoid arthritis. It prevents the brush from rotating because of the individual's reduced grip strength (Figs $2 \mathrm{a}$ and $2 \mathrm{~b}){ }^{13,14}$ Other simple and successful methods of adapting the toothbrush grip include the use of sponges, 


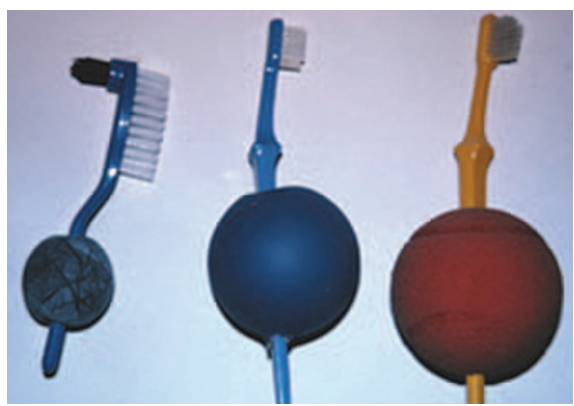

Fig. 5 Denture brush and regular toothbrush handles enlarged using soft rubber balls to give improved hand grip (reproduced with kind permission of Quintessence Publishing Co., Ltd)

plastazote tubing (Fig. 3), ${ }^{8,13}$ bicycle handlebar grips (Fig. 4), ${ }^{8}$ wrapping the handle in tape $\mathrm{e}^{8}$ or pushing it into a soft rubber or styrofoam ball (Fig. 5), such as those available from craft shops. ${ }^{9}$

Manipulation - for those patients who can position a toothbrush but cannot manipulate it sufficiently to clean all the surfaces of the teeth, double-headed brushes are useful and commercially available (Figs 6a and 6b). They remove plaque simultaneously from buccal and lingual/palatal surfaces using only back-and-forth movements., ${ }^{1,9}$ Depending on the design chosen, a conventional brush may still be required for occlusal plaque removal. ${ }^{13}$ Kaschke et al. ${ }^{15}$ used a blind, cross-over trial to look at the effectiveness of different toothbrushes and showed that a three-headed brush (such as the 'Superbrush') performed best for adults who otherwise required help with their toothbrushing. ${ }^{15}$ TePe provide a range of 'Special Care' toothbrushes with heads of differing sizes and a useful clip-on handle adaptation (Figs 7a and 7b).

\section{Limited shoulder or arm movement}

For this group of people, where there is limited arm and hand movement, the objective is to lengthen the handle of the brush with a material strong enough to maintain the brush in contact with tooth surfaces so as to apply sufficient lateral pressure to remove plaque effectively. ${ }^{9} \mathrm{~A}$ variety of methods have been described, including using a wooden splint, ${ }^{8}$ a length of thick wooden dowling with the brush handle cemented inside it, ${ }^{9,16}$ and two brushes fixed together using heat, glue and tape as required..$^{9,16}$

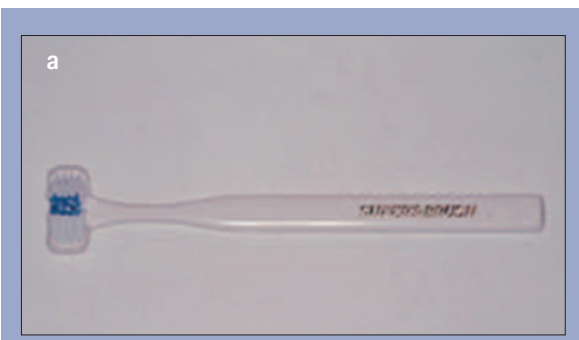

Fig. 6a Double-headed brush for improved plaque control in people who would otherwise require assistance with toothbrushing

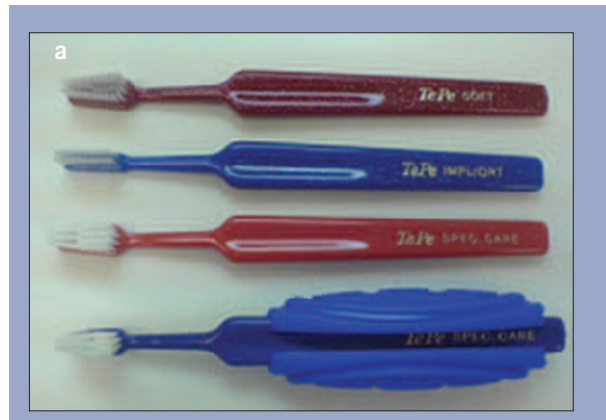

Fig. 7a Range of TePe special care brushes with heads of differing sizes and clip-on handle adaptation

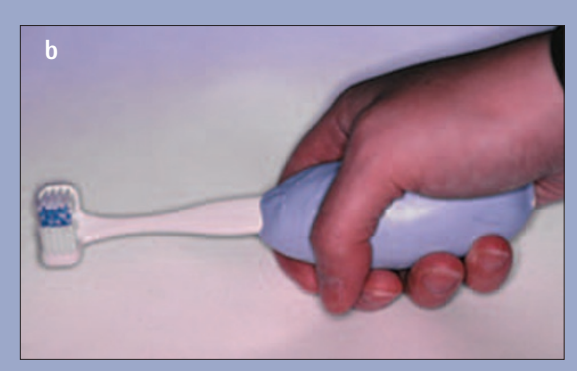

Fig. 6b Double-headed brush with modified handle (using silicone putty) for ease of grip

\section{Concentration, cognitive or memory difficulties}

For patients with concentration, cognitive or memory difficulties, remembering to carry out the task and for how long are important steps. The use of egg timers, watch alarms and the like can be useful fo $r$ motivation and to ensure that sufficient time is dedicated to the task of oral hygiene. ${ }^{11}$ The use of a daily routine involving a song or music of the required length or step by step instructions delivered via audio tape have also been demonstrated to be useful and effective adjuncts to oral care. ${ }^{12}$

\section{Electric toothbrushes}

A Cochrane review concluded that powered toothbrushes with a rotation-oscillation action are more effective than manual brushes in reducing plaque and gingivitis in the short-term, and gingivitis in the long-term. ${ }^{17,18}$ They are reported to improve compliance and it is advised that the user should receive specific instruction to ensure correct use. ${ }^{18}$

A powered toothbrush can be a beneficial oral hygiene adjunct for many people with disability as its action compensates for the loss of skilled

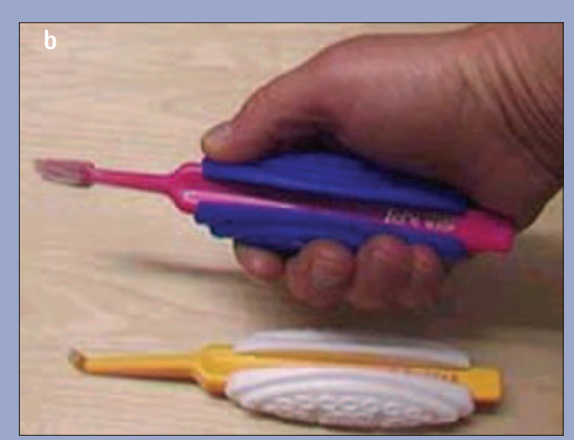

Fig. 7b TePe interdental brush showing handle for easy holding manipulation required when using an ordinary brush (Fig. 8). ${ }^{10}$ Additionally it can motivate patients with a fascination for electrical items and alarms, such as adolescents and people with Asperger's syndrome, ${ }^{9}$ and it is useful for those patients with muscular disease or fatigue where they often do not have enough strength to brush..$^{10}$ Electric brushes tend to have larger diameter handles, making them easier to grip than manual ones. However, a disadvantage is that they tend to be heavier and they do not suit everyone. ${ }^{13}$ Other disadvantages include the cost, and the on/off mechanism, which can be difficult for people who have problems grasping objects to use. In addition, the vibrations cannot be tolerated by some patients. ${ }^{9}$

\section{Flossing and inter-dental care}

With time and repeated instruction, many patients with learning disabilities can learn to use dental floss and some can learn to use inter-dental aids. ${ }^{9}$

Typically, flossing is a two-handed task and conventional flossing is difficult, if not impossible, for people with manual impairments. ${ }^{1}$ However, single use or self-threading floss holders may 
help overcome some of the difficulties and can make flossing possible for patients with limited dexterity or the use of only one hand. ${ }^{9}$ Patients with poor motor control require careful instruction and preliminary supervision to prevent soft tissue damage. ${ }^{9}$ People with hemiplegia can find interdental brushes easier to use than floss as their handles can be modified using any of the methods previously listed. Also they are commercially available with holders suitable for people with impairments. ${ }^{11}$

Oral care can become a challenging task for people who have impairments as a consequence of stroke. Physical weakness, lack of co-ordination and the cognitive problems that can accompany a stroke may prevent a person from maintaining good oral hygiene independently. ${ }^{19}$ Many obvious areas may be overlooked. For example, opening a tube of toothpaste can be almost impossible, and both toothpaste pumps and dispensers are easier to manage than a tube with a cap (Fig. 9). Toothpaste dispensers are also available with a slot for the toothbrush, such that the device dispenses the appropriate amount of paste when the dispenser lever is pressed..$^{20}$ This could be used equally successfully with tubes of denture cleaner or fixative.

\section{Care of removable prostheses}

Denture care is another challenge for people with poor dexterity or hemiplegia, with a risk of dropping or damaging their prosthesis during cleaning, or the inability to hold a denture and brush at the same time. Partially filling the sink with water, or placing a face cloth in the sink, acts as a cushion should the denture be dropped during cleaning. ${ }^{9}$ Denture brush handles can be adapted by any of the methods described for regular brushes. Alternatively a nail brush may be used instead of a standard brush, provided all denture surfaces can be reached. ${ }^{9}$ Denture brushes are available with suction cups that allow them to be fixed to the side of the basin, just below the water level, so that dentures can be cleaned using a one-handed technique of moving the denture against the brush. ${ }^{16}$ Individual ultrasonic baths, which can be used to further aid denture debris removal, are available commercially but are costly. ${ }^{21}$

\section{Prevention}

Prevention of oral disease is of paramount importance for individuals with disabilities, not only to prevent oral disease and its complications, but also to obviate the need for operative intervention and any associated difficulties. ${ }^{22}$

People with multiple or chronic disease often have reduced salivary secretion. Both the likelihood and the degree of xerostomia increases when a number of drugs are taken concurrently ${ }^{1}$ with negative consequences for oral health. Dry mouth can cause the gingivae and mucous membranes to become fragile, easily traumatised and painful, ${ }^{10}$ impact-

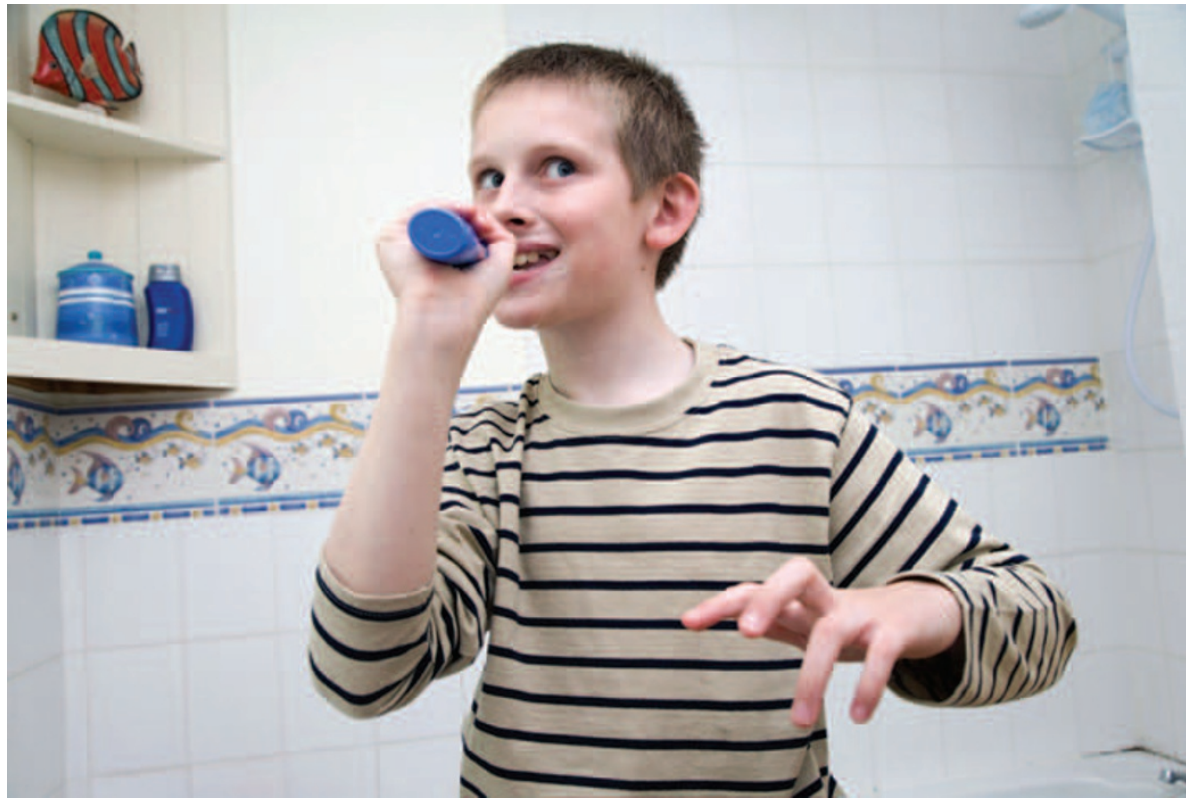

Fig. 8 Boy with Asperger's syndrome using a large-handled electric toothbrush ing on oral hygiene, food intake and nutrition. To avoid this situation, the oral cavity should be moistened with a saliva substitute or other lubricants according to the preference of the patient. Care must be taken to choose the appropriate product, for example avoiding those with citric acid for dentate persons ${ }^{23}$ and porcine products for vegetarian, Jewish and Muslim individuals. ${ }^{1}$

Altered quality and/or reduced quantity of saliva carries with it a higher risk of dental caries. The three cornerstones of preventive dentistry for patients at high risk of developing caries are delivery of fluoride, good oral hygiene and well thought out diet. ${ }^{10}$ Ahlborg ${ }^{10}$ believes that, while it is often difficult to adapt or influence the specialised diet and there is variable success with strategies for oral hygiene for patients with disabilities, it is never impossible to add fluoride into a daily regime. ${ }^{10}$

\section{Fluoride}

Toothpaste is the most common way to introduce fluoride into the daily oral health regime. For individuals unable to tolerate toothpaste, a toothbrush dipped in $0.2 \%$ fluoride mouthwash can be used to provide daily fluoride application. ${ }^{10}$ An extensive Cochrane review of efficacy of caries reduction with topical fluoride combinations versus single topical fluoride found that topical fluorides (mouthrinses, gels or varnishes) used in addition to fluoride toothpaste reduce

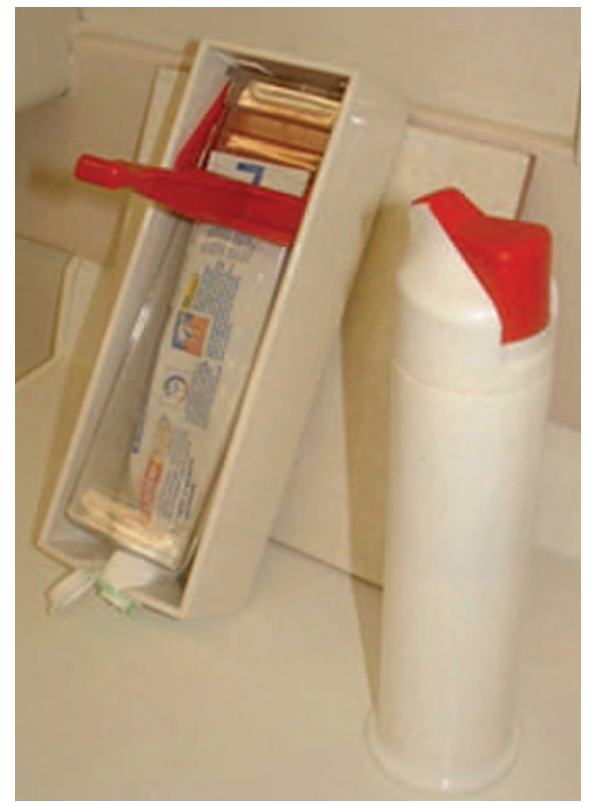

Fig. 9 Toothpaste pump and dispenser 
caries by an average of $10 \%$ more than fluoride toothpaste used alone. ${ }^{24}$

Fluoride varnish is a particularly useful form of topical fluoride in patients with impairments and intellectual disabilities, since its application does not require prolonged isolation of the dental arch and it is moisture tolerant, setting in the presence of saliva..$^{10}$ Duraphat (2.26\% fluoride) varnish has been shown to be effective when applied bi-annually. ${ }^{24}$ However, caution is required as patients with an allergy to sticking plaster may exhibit hypersensitivity to colophony, which is present within the varnish. ${ }^{25}$ Toothpastes containing high fluoride concentration (5,000 ppm), such as 'Colgate Professional', are available commercially for daily use.

\section{Other caries reducing products}

Other professionally-applied effective preventive measures include concentrated chlorhexidine varnishes (40\% EC40) and 1\% chlorhexidine with 0.1\% thymol (Cervitec). Although subject to variability in patient response, ${ }^{26}$ both products inhibit Streptococcus mutans in inter-proximal plaque and saliva ${ }^{27,28}$ and may be applied around the gingival margin for sustained anti-cariogenic effects. ${ }^{10}$ Casein phosphopeptide-amorphous calcium phosphate complexes (CPP-ACP) have been shown to aid re-mineralisation in dental erosion..$^{29,30}$ GC Tooth Mousse, which contains Recaldent ${ }^{\odot}(\mathrm{CPP}-\mathrm{ACP})$, is being suggested as particularly suitable for patients with a high caries risk due to xerostomia and low saliva $\mathrm{pH}$. It can be applied daily using a dry gauze-protected finger or a cotton bud, making it suitable for use in patients who find cooperation difficult or who may be intolerant of fluoride trays. ${ }^{31}$

Chlorhexidine may be indicated to control gingivitis in order to compliment, or to compensate for, the brushing of teeth. Many patients may be incapable of rinsing due to cognitive problems, dysphagia, or poor neuromuscular co-ordination. In these cases, swabbing the gingivae with $0.2 \%$ solution is an effective way of modifying application and is well tolerated by patients with disabilities. ${ }^{32}$ Alternatively, 1\% chlorhexidine gel can be applied with a finger, toothbrush or in individually made soft plastic trays, ${ }^{10}$ and in very unco-operative patients, chlorhexidine spray may be useful. ${ }^{1}$

\section{Sugar in medicines}

Long-term use of sugar-based liquid medication is of particular concern as a caries risk in people with longstanding and chronic conditions. ${ }^{1}$ Although sugars are used to improve the shelf-life and to make medicines more palatable and acceptable, drug companies have responded to the demand for sugar-free medicines. Whilst the British National Formulary (BNF) specifically indicates medicines that are sugar-free, those most commonly prescribed by doctors and dentists and sold over the counter by pharmacists are the sugar-based preparations. ${ }^{33}$ The onus is on the prescriber to specify an appropriate preparation, ${ }^{1}$ as current legislation is such that if a prescription for a generic medicine does not specify 'SF' (sugar-free), the sugarcontaining form of the drug will automatically be dispensed. ${ }^{33}$

There are numerous studies showing that children taking long-term oral medication have significantly more dental caries than their none medicinetaking siblings. ${ }^{34}$ The prescription of sugar-based medication for the increasing number of dentate older people is also a matter of concern, more so if it, or medication they are already taking, causes xerostomia. ${ }^{35}$ Any dentate patient prescribed sugar-containing medicines should be warned of the risk of caries and advised to ask their doctor if a sugar-free preparation is available. If this request cannot be accommodated, appropriate caries preventive measures need to be put in place. Also, taking liquid medication through a straw, if its viscosity permits, reduces its potential for contact with the teeth. ${ }^{1}$

More recently, the prolonged administration of glyceryl tri-nitrate (GTN) preparations for the treatment of ischaemic heart disease has been associated with localised caries in the area where the tablet is retained. ${ }^{36}$ The tablet induces a rapid fall in $\mathrm{pH}$ and unusually, the lactulose in this form of preparation becomes considerably more cariogenic. Susceptible individuals who regularly use this from of GTN should be targeted for preventive advice. ${ }^{1}$

\section{Dietary issues}

Some people with disability and longterm neurological conditions (such as cerebral palsy and Parkinson's disease) have feeding difficulties and fail to gain weight. Often, they are recommended a high calorie intake from energy-rich foods and are advised to eat little and often. Energy-rich food supplements prescribed to ensure adequate nutritional intake have a high carbohydrate and sugar content. ${ }^{37}$ People are advised to sip them at frequent intervals throughout the day and, where there is a problem with swallowing, the liquid may be thickened to avoid the likelihood of its aspiration. This reduces oral clearance and increases the risk of caries yet further. ${ }^{38}$ It is therefore important to check the contents for cariogenic sugars and ensure preventive measures are advised or instituted as required.

The impact of thirst and eating for consolation or comfort on oral health is often overlooked in patients with chronic conditions. This behaviour can result in caries and dental erosion because of frequent intake of acid sweets and drinks. ${ }^{10}$ Management strategies include recommending sipping water at regular intervals during the day and chewing sugar-free gum, where possible. ${ }^{39,40}$ It can be difficult and sometimes impossible to change food fads associated with autistic spectrum disorders and it is particularly important to work with individuals and their families or carers to ensure that a rigorous preventive regime is adhered to.

\section{CARERS}

Caring for the mouth requires a certain level of understanding and a certain level of manual dexterity. Both learning and functional disabilities can restrict access to dental care and pose limitations on the management of personal hygiene. Mouth care is an essential part of personal daily care, impacting as it does on communication, dignity, self-esteem, self-confidence, appearance, dietary enjoyment, nutrition, comfort and general health. ${ }^{1}$ A survey that took account of the views of nursing personnel, carers and dentists regarding priorities for oral healthcare for people with dementia indicated that although the groups had different 
priorities, they were all concerned about oral well-being. ${ }^{41}$ Nursing staff felt that being able to eat was important, relatives were much more concerned about social behaviour and communication, including aesthetics, speech and fresh breath, whereas dentists' primary concern was freedom from oral pain.

Where people are dependent as a result of disability or chronic illness, the primary healthcare professional (including members of the dental team) plays a role in motivating and encouraging individuals and their carers in the provision of daily oral care through practical advice and assistance. A prompt, in the form of a reminder or encouragement, or supervision during the task ${ }^{42}$ may be all that is needed for some people, for example those with mild to moderate learning disability and early stages of dementia. An oral health program for people with psychiatric disabilities showed that whilst the provision of mechanical toothbrushes improved oral hygiene, the combination of mechanical toothbrush, instruction and reminders resulted in additional improvements. ${ }^{43}$ However, where a person with a disability cannot carry out effective oral care techniques they will be dependent upon a carer for their daily oral hygiene needs.

\section{Carer attitudes towards mouth care}

Carers may be 'professional' (for example, care home assistants) or 'non-professional', usually family members such as a sibling, parent or spouse. Although carers believe that dental care is important, they can be reluctant to use dental services as they perceive the dental team to be ill-equipped to deal with people with disability. ${ }^{44,45}$ Whittle $^{44}$ states that carers and relatives felt reassured when the dentist was fully aware of the nature of disability, indicating that these concerns can be overcome. ${ }^{44}$ Thus, it is important for the dental team to be informed and to be perceived as such.

It is well documented that carers find the provision of oral care difficult. The reasons include carers' attitudes towards dental treatment and oral hygiene, ${ }^{46}$ how they see their role in mouth care, undermining of autonomy and independence, fitting the task into an already busy routine, practical skills and problems and concerns about being bitten, finding the task unpleasant, and the possibility of hurting the individual. ${ }^{47}$

The value of oral hygiene programmes for dependent adults has been demonstrated. For example, Budtz-Jorgenson et $a l .{ }^{48}$ showed that an oral health preventive program in frail and dependent residents in a long-term care facility was effective in reducing the colonisation of the oral mucosa and dentures by Candida and thereby improving the health of the oral mucosa. ${ }^{48}$ However, there are mixed reports on the value of oral hygiene training for care staff in care homes. Simons et al. ${ }^{49}$ described carers' baseline knowledge about oral health as poor, but high one week after an oral health training programme. ${ }^{49}$ Although the programme was well received, no changes in oral health practice resulted and there was no measurable improvement in the oral health of residents after carer training. They concluded that barriers to practice of oral care by carers remained and training (even when including practical skills, evaluation by peers and a high knowledge gain) failed to reduce these barriers. Brady et al. ${ }^{50}$ had a more positive outcome, finding that provision of oral care training for carers looking after people with neurological conditions (such as stroke) in a nursing home setting, improved their knowledge of, and attitudes towards, the provision of oral care. ${ }^{50}$ The residents' dentures were cleaner, but no other oral hygiene measures changed. Frenkel's findings have been the most positive..$^{51}$ In her study, the majority of carers thought that clients had a right to good oral health, accepted the carer's role in helping clients with oral and denture hygiene, but recognised that oral healthcare provision was deficient. ${ }^{51-53}$ Carers were critical of the lack of care homes' arrangements for routine professional dental checks, lack of commitment to staff training, low standards of oral healthcare by colleagues, and lack of provision of oral hygiene aids and cleansing materials for clients. Despite showing that most of the residents who required help with oral health did not receive it, and that residents' plaque levels and associated dental disease were high because staff did not perform effective oral healthcare appropriate to residents' needs, ${ }^{52}$ an oral healthcare education programme was well received. It resulted in improved oral healthcare knowledge and attitudes, as well as improved delivery of oral healthcare, ${ }^{53}$ demonstrating that access to information and training can help reduce the barriers to oral hygiene.

Other suggested ways of reducing barriers to oral hygiene provision by professional carers include: the use of consolidated and organised care plans, the elements of which consider implementation of a single holistic assessment process; utilisation of oral risk assessment tools; development of team and multi-agency working; understanding, and safe address, of consent and restraint issues; access to oral hygiene equipment; support for the implementation and maintenance of aggressive preventive regimes; and robust systems for referral to oral healthcare services. ${ }^{46}$

The implementation of The Care Standards Act (2000), ${ }^{54}$ through the National Minimum Standards for Care Homes for Older People, ${ }^{42}$ has facilitated oral healthcare within care homes by setting out standards that cover health and personal care. Standard 8 refers to 'the provision of personal care in a way which maintains and respects privacy, dignity and lifestyle', with particular regard to assisting with 'bathing, washing, shaving and oral hygiene'. Additionally, standard 8.2 states that 'Care staff should maintain the personal and oral hygiene of each service user and, wherever possible, support the service user's own capacity for self-care'. In effect, this provides a duty of care for care homes to ensure the oral hygiene of their residents. Members of the dental team visiting care homes to provide dental care may need to remind carers of this duty of care, and may also need to provide them with the knowledge and skills required to deliver it.

\section{Autonomy and respect}

Each person with disability is an individual with their own experiences of life, their own needs and feelings, and their own likes and dislikes. It is important 
to treat people as adults and with courtesy and respect, however profound their disability. The Alzheimer's Society suggests that autonomy and respect can be provided by: ${ }^{55}$

- Being kind and reassuring, without talking down or patronising

- Avoiding scolding or criticising the person as this will make them feel small, for example when oral or denture hygiene is poor

- Respecting privacy, for example seeing the individual in a private room on a domiciliary visit in a care home setting.

There can be a tension for carers between the perception of importance of mouth care and the need to encourage and maintain independence, with added concerns about how to do it right. ${ }^{47}$ This view needs to be put in the context of the benefits provided by good oral hygiene and fresh breath. Essentially carers can find carrying out oral hygiene challenging, particularly when it is for a family member. Practical advice on how to do it helps to mitigate the challenge.

\section{How to clean someone else's teeth}

When assisting an individual with tooth-brushing, the technique will vary depending on the individual concerned. Many people prefer to wear disposable 'examination' gloves while carrying out this task, as they find the feel of saliva and presence of food debris unpleasant.

A useful method of assisting another person with their tooth-brushing is to: ${ }^{46}$

- Seat her/him on a dining-style chair

- Stand behind her/him with the head cradled against the carer's body by an arm to provide neck support and control over head movements (Fig. 10)

- Gently pull back the cheek with the other hand to improve vision and access

- Brush the teeth using a damp smallheaded, medium-textured toothbrush or cloth/flannel wrapped around a finger, depending on what can be tolerated

- Use a damp cloth/flannel wrapped around a finger to gently remove any food trapped in the cheek pouches or under the tongue.

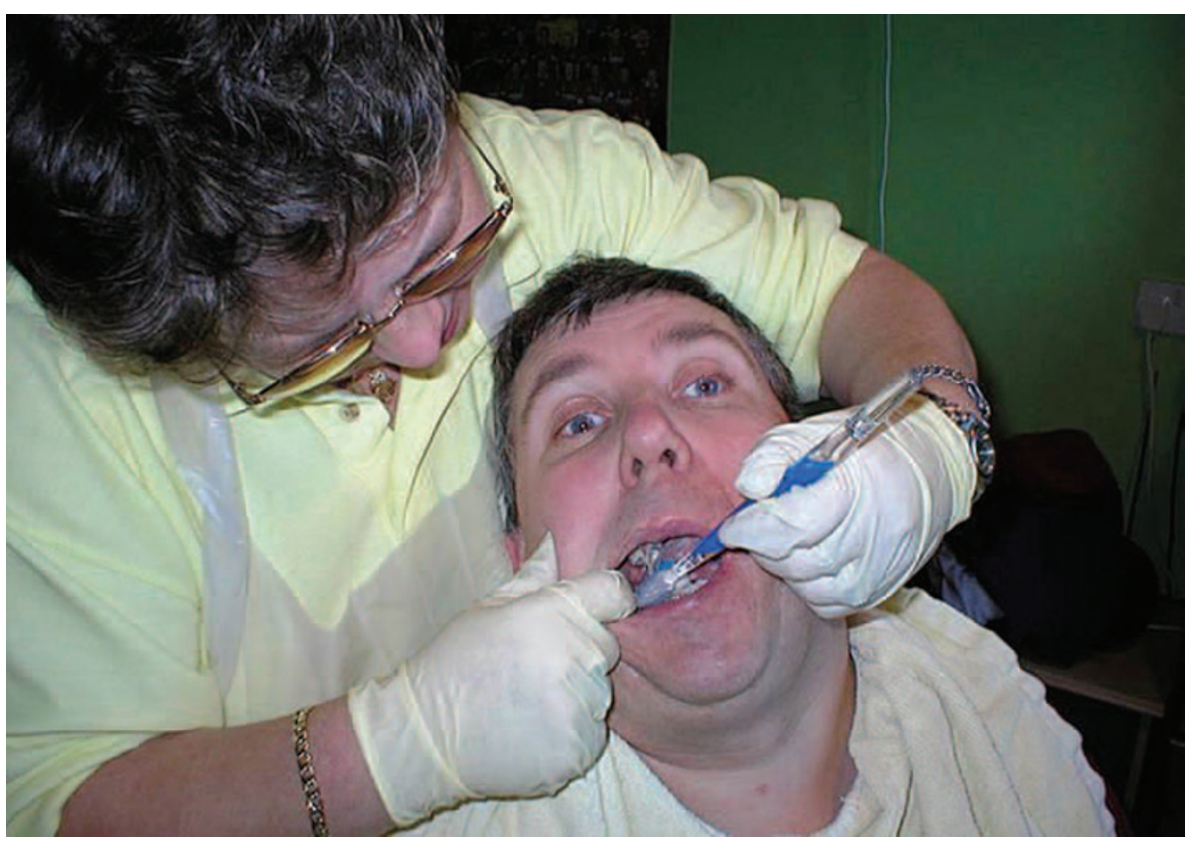

Fig. 10 Carer cleaning the teeth of a person with a disability such that they can no longer perform this task

If there is difficulty with co-operation in opening the mouth or biting onto the brush, a finger guard can be used to prop open one side of the mouth while brushing the other. In cases where the disabled person finds it difficult to cooperate, it may be necessary to enlist the help of another person to gently hold their hands away from the mouth.

\section{THE DENTAL TEAM PROFESSIONALS}

This section considers the responsibility of the dental team per se and its responsibilities for liaising with, and education of, other healthcare professionals about oral healthcare in a holistic context.

There is a clear shift in national policy, with the direction of travel towards 'personalised services' and a shift from a limited menu of health and social care services to a mainstream system focused on prevention, early intervention, enablement and high quality personally tailored services. ${ }^{56}$ Government aspiration is for everyone to have maximum choice and control over the support services they receive. ${ }^{57,58}$

The current Darzi review of the NHS ${ }^{59}$ recognises that the relationship between health, social care and wider community services will be integral to the creation of this personalised care system. It states that there should be agreed and shared outcomes which ensure that, irrespective of illness or disability, people are supported to live independently; stay healthy and recover quickly from illness; exercise maximum control over their life; participate as active and equal citizens, both economically and socially; have the best possible quality of life, irrespective of illness or disability; and retain maximum dignity and respect. For the provision of oral healthcare for people with disabilities to follow this paradigm shift, it requires dental service providers to work in new ways - using extended teams and taking responsibility for educating that team in how to incorporate oral health into the holistic care of each individual with a disability.

\section{The dental workforce}

The present increase in the number of dentists and dental care professionals (DCPs) will help meet the greater demands placed on dental services by the increasing number of increasingly dentate people with disability. However, any resultant improvement in the dental care of people with disability will only occur if the potential workforce has appropriate education and training at both the undergraduate and postgraduate levels. There is also concern about the oral health of people with disability who are dependent on others for daily oral care. Improvements in oral hygiene in this client group can only be addressed 
by adequate and appropriate training for healthcare professionals involved in direct patient care. The role of DCPs will be pivotal to the provision of preventive programmes for people with disability and their carers.

\section{Other health and social care workers}

Whilst members of the dental team are the acknowledged experts in oral care, they form only a portion of the range of health and social care workers involved in the care of people with disability. For example, many people with a disability or their carers will consult a pharmacist on health issues before seeing a doctor, and will often consult their general medical practitioner (GMP) with oral problems before seeing a dentist. ${ }^{60}$ Thus, the potential of pharmacists and GMPs in promoting good oral healthcare, or inadvertently causing it to decline, should not be underestimated. ${ }^{60}$ The responsibility in educating them regarding these matters sits firmly with the dental team. It can be done through inclusion of oral health information within their undergraduate and continuing education courses, and perhaps more importantly, through reminders related to individual patients via requests for sugar-free medicines and, where possible, medicines without xerostomic side-effects.

More extended levels of care can be needed for people confined to home, including help with oral hygiene and preventive measures. Carers, community nurses, social workers and occupational therapists should all have appropriate training in order to be capable of providing this help. ${ }^{61}$ Additionally, they are often the first people to realise that the individual has an oral problem, and need to know how to initiate appropriate help. There are oral health risk assessment tools that can be recommended to facilitate this process. ${ }^{1,46}$ Creation of an appropriate understanding of the contribution of oral health to improved general health and well-being will also help to address these issues. ${ }^{60}$

\section{Undergraduate dental education}

While a minority of graduates are likely to have an interest in pursuing a postgraduate training pathway in special care dentistry, ${ }^{62}$ it is acknowledged that all graduates will encounter people with disabilities during their working lives. They require sufficient education to provide them with the ability to take a history, make a diagnosis and prepare a treatment plan for people with impairments. ${ }^{63}$ At the point of graduation, they should be competent to carry out clinical examination and treatment planning, taking sensitive account of acquired or developmental impairments; examine a patient with mild to moderate intellectual and/or physical impairments; determine any adjuncts required to provide dental care; produce a pragmatic oral care plan that considers their individual needs; and provide basic dental care. ${ }^{63}$

Evaluation of undergraduate teaching has revealed a previously ad-hoc approach to education in special care dentistry and found that the principles of holistic care of the so-called 'special needs' patient was lacking in many dental undergraduate curricula. ${ }^{64-66}$ Thompson et al. ${ }^{67}$ felt this was unacceptable and suggested that undergraduate training should provide sufficient exposure to enable students 'to recognise their duty of care in the attainment of achievable treatment outcomes for patients with specific medical, physical or mental health problems and to know the appropriate pathways for referral of patients whom they are unable to treat or who require further assessment. ${ }^{97}$ This view has been echoed by the Quality Assurance Agency for Higher Education, who included 'special needs' in their benchmarking document. ${ }^{68}$ The General Dental Council's undergraduate curriculum document, The first five years, ${ }^{63}$ although not prescriptive, outlines subject matter that must be an integral part of a dental course, including many areas pertinent to special care dentistry. Consequently, in 2002 the British Society for Disability and Oral Health produced a framework document that has served as a template for dental schools revising their curricula. ${ }^{62}$ The objectives of the framework centred on demonstrating positive attitudes towards diversity and included, for the first time, disability awareness, public health aspects of special care dentistry and relevant ethics and legislation.
Since The first five years was introduced, there has been widespread pressure within the dental schools' curriculum to incorporate newer areas and innovative ways of teaching special care dentistry, within the constraints of finance, teaching space and time. A number of schools have responded. For example, in Dublin ${ }^{69}$ undergraduates have access to a comprehensive e-learning resource and take part in small group weekly online tutorials via a special care real-time web forum. They spend time in special care clinics within the hospital and visit outreach clinics working alongside senior special care dentists in the community. King's College London Dental Institute provides a short lecture course before students spend time in the department of special care dentistry providing treatment with and without conscious sedation. Student feedback has been hugely favourable, with the most valued elements of the course being the holistic approach, ie seeing the patient and not just a mouth, realising that something they were anxious about can be both manageable and enjoyable, and the high level of clinician and dental nurse support, which makes them feel part of a team. ${ }^{70}$ The course is complemented by outreach clinic and domiciliary visits with senior clinicians in the local community special care dental service. ${ }^{71}$ Cardiff ${ }^{69}$ has recently introduced a comprehensive special care curriculum with a core lecture course and dedicated student sessions in the sedation and special care suite, whereas Birmingham ${ }^{69}$ has elected for a didactic special care lecture series alongside innovative workshops on instant ageing and patient management using role play with professional actors.

Special care dentistry is also required as part of the GDC curricula for dental nurses, hygienists and therapists, thus enabling them to participate as informed members of the dental team in the provision of oral healthcare for people with disabilities. $^{72}$

\section{Postgraduate education}

In the past, dentists have not always been able or willing to provide dental care for patients requiring special care. One of the key reasons given for this 


\begin{tabular}{|c|c|}
\hline Institute & Programmes \\
\hline Royal College of Surgeons of England & Diploma in Special Care Dentistry \\
\hline Royal College of Surgeons of Edinburgh & Membership in Special Care Dentistry \\
\hline University of Bristol & BUOLD course - special care dentistry module \\
\hline King's College London Dental Institute & MSc in Special Care and Sedation \\
\hline UCL Eastman Dental Institute & MSc in Special Care Dentistry \\
\hline UCL Eastman Dental Institute & $\begin{array}{l}\text { Postgraduate Certificate/Diploma in } \\
\text { Special Care Dentistry }\end{array}$ \\
\hline
\end{tabular}

is lack of training or experience. ${ }^{73}$ The development of undergraduate training in special care dentistry has begun to address this issue, but for those dentists who qualified prior to such curriculum changes there are now many opportunities for postgraduate study to refresh or further develop their knowledge and skill base.

The two specialist societies for special care dentistry, the British Society for Disability and Oral Health (BSDH) and the British Society of Gerodontology (BSG), have developed a number of guidelines focusing on the provision of high quality oral healthcare for people with a variety of needs, ranging from mental health problems to terminal illness. ${ }^{74-80}$ Additionally, they each run two scientific study days a year, aimed at all members of the dental team.

Team work is central to the successful management of patients with disabilities and courses for the education and training of dental nurses in special care dentistry are being established regionally. The Post-Registration Certificate in Special Care Dental Nursing is a modular certificate, available throughout the UK. It comprises a ten day programme of theoretical instruction and mentoring, supplemented by a locally completed portfolio of experience consisting of logged cases, evidence of competences and finally a written examination. ${ }^{81}$ The course utilises an innovative learning process that draws on the participant's own work-based experiences. Courses for other DCPs are in development.

\section{Postgraduate training}

There are a variety of postgraduate training programmes currently running in the UK and Ireland. Depending on the chosen programme these can be undertaken via modular, distance learning, full- or part-time study, or attendance at day courses. Many courses in special care dentistry are accredited towards the FGDP(UK) Career Pathway and participants may be eligible for full or partial exemption from the case component of the FFGDP(UK) assessment if they hold one of the accredited qualifications ${ }^{82}$ (Table 2). For example, Bristol University includes a course for dentists interested in improving knowledge and skills in special care dentistry in their BUOLD programme, designed specifically to be attractive to busy practitioners. Each course combines a structured programme of around 80 hours of academic study with workplace activity. Its aim is to enable dentists to become confident in managing patients requiring special care and to provide an equitable dental servoral care, the importance of team working and effective communication.

\section{Specialist training}

The General Dental Council for the UK has added special care dentistry to the UK list of dental specialties. Full recognition of the specialty is due in September 2008, at which point the mediation process for entry to the specialist list will open for a period of two years, giving those people with experience, knowledge and skills in this field an ice. It emphasises the holistic approach to opportunity to apply. Local postgraduate deaneries have the responsibility of recognising training posts and trainers, whilst the Specialist Advisory Committee for Special Care Dentistry has the responsibility for curriculum development. Recognition of special care dentistry as one of the UK dental specialties provides a career structure through a specialist training pathway that will encourage dentists with an interest in this field to embark on a career in special care dentistry.

A number of dental schools run courses in special care dentistry which can either contribute to, or provide the three year specialist training necessary for, entry to the specialist list. Kings College London Dental Institute runs a two year Master of Science (MSc) programme in sedation and special care dentistry that provides academic, research and clinical elements. The latter are in-house as well community-based, through a number of close links with community and other dental services. The Eastman Dental Institute, which runs an established MSc course in special care dentistry, has recently established modular Certificate and Diploma courses, providing two and three modules of accreditation, respectively, in special care dentistry. Trinity College Dublin offers a taught doctorate in Dental Surgery - Special Care Dentistry (D.Dent.Ch.) which is three years full-time and five years part-time. In addition to general and oral/dental aspects of special care dentistry, clinical attachments with outside agencies and hands-on clinical training at the Dublin Dental School, the programme incorporates modules from the Developmental Disabilities Graduate Diploma course at University College Dublin and a significant research component.

\section{Research}

Research is a major influence in the development of new techniques in clinical dentistry. ${ }^{83}$ Both BSDH and BSG encourage research in special care dentistry, including gerodontology. The Journal of Disability and Oral Health $(\mathrm{JDOH})$ is the official publication of both the BSDH and the International Association of Disability and Oral Health. Gerodontology is the official journal of BSG 
and the European College of Gerodontology. Both publications are dedicated to improving the quality of life and oral health of people with disability through the advancement of knowledge and expertise in the area of special care dentistry. They aim to give the reader clinically and scientifically-based papers, practical management techniques, case reports and other original work relating to all aspects relevant to the comprehensive oral care of people with disabilities.

In order to encourage the innovator in their field, the novice academic, or the experienced clinician with a cautionary tale to tell, BSDH also has a number of awards to support projects that improve or impact on the delivery of primary oral healthcare to individuals with a disability. Details are available from the BSDH website. ${ }^{84}$

\section{Useful websites}

British Society for Disability and Oral Health: www.bsdh.org.uk British Society for Gerodontology: www.gerodontology.com

The illustrative material used in Figure 8 is attributed to www.johnbirdsall.co.uk. The authors wish to thank Dr Chris Dickinson, Consultant in Special Care Dentistry, for providing the illustrative material for figures $2 a$ and $7 a$; and Qunitessence Ltd for kindly permitting reproduction of Figures 2b, 3 and 5 from Quintessentials Clinical Practice 5 - Special Care Dentistry.

1. Griffiths J, Boyle S. Holistic oral care - a guide for health professionals. Sections 2-3. London: Stephen Hancocks Ltd, 2005.

2. Dyspraxia Foundation website. 2008. http:// www.dyspraxiafoundation.org.uk

3. Brookes G. What is dyspraxia? Chapter 1. London: Continuum International Publishing Group, 2005.

4. Hicks R. Dyspraxia. BBC Health website 'Conditions' section, 2008. www.bbc.co.uk/health/conditions/dyspraxia2.shtm

5. Dyspraxia Ireland website. 2008. www.dyspraxiaireland.com

6. British Dyslexia Society website. 2008. www.bdadyslexia.org.uk

7. National Centre for Learning Disabilities website. 2008. http://www.ncld.org

8. National Institute of Dental and Craniofacial Research. Practical oral care for people with developmental disabilities publication series. Bethesda MD: National Institute of Dental and Craniofacial Research, 2008. http://www.nidcr.nih.gov/OralHealth/Topics/DevelopmentalDisabilities/

9. Wilkins E M. Patients with special needs. In Clinical practice of the dental hygienist. Section VII. Philadelphia: Lippincott, Williams \& Wilkins, 2004

10. Ahlborg B. Practical prevention. In Disability and oral care. Chapter 4. London: FDI World Dental Press, 2000.

11. Mun-H Center website. 2008. www.mun-h-center.se

12. Dougall A J. Oral care for neurologically impaired adults. Paper presented at the Irish Association for Disability and Oral Health Summer Conference, Dublin, 2006.

13. Fiske J, Dickinson C, Boyle C, Rafique S, Burke M. Managing the health of patients with physical disabilities. In Special care dentistry pp 9-26. London: Quintessence Publishing, 2007.

14. Dickinson C, Millwood J. Toothbrush handle adaptation using silicone impression putty. Dent Update 1999; 26: 288-298.

15. Kaschke I, Klaus-Roland J, Zeller A. The effectiveness of different toothbrushes for patients with special needs. J Disabil Oral Health 2005; 6: 65-71.

16. Abledata. Extended handle toothbrush webpage. http://www.abledata.com/abledata.cfm?pageid $=19327 \&$ top $=12298$ \& productid $=79067$ \&trail $=22,11860,12287 \&$ tdiscontinued $=0$ (accessed 23 June 2008)

17. Robinson P, Deacon S, Deery C et al. Manual versus powered toothbrushing for oral health. Cochrane Database Syst Rev 2005; 1: CD002281. DOI: 10.1002/14651858.CD002281.pub2.

18. Davies R. Manual versus powered toothbrushes: what is the evidence? Dent Update 2006; 33: 159-162.

19. Brady M, Furlanetto D, Hunter R, Lewin S, Milne V. Improving oral hygiene in patients after a stroke. Stroke 2007; 38: 1115-1116.

20. Selzer M, Clarke S, Cohen L, Duncan P, Gage F (eds). Textbook of neural repair and rehabilitation. Part A2. Cambridge: Cambridge University Press, 2006.

21. Davies A, Finlay I. Oral care in advanced disease. Chapter 3. Oxford: Oxford University Press, 2005.

22. Scully C, Dios P D, Kumar N. Special care in dentistry. Chapter 2. London: Churchill Livingstone, 2007.

23. Scully C, Cawson R. Medical problems in dentistry. Chapter 7. Oxford: Wright, 1999

24. Marinho V C C, Higgins J P T, Sheiham A, Logan $S$. Combinations of topical fluoride (toothpastes, mouthrinses, gels, varnishes) versus single topical fluoride for preventing dental caries in children and adolescents. Cochrane Database Syst Rev 2004; 1: CD002781. DOI: 10.1002/14651858. CD002781.pub2.

25. Sharma P. Allergic contact stomatitis from colophony. Dent Update 2006; 33: 440-442.

26. Ribero L, Hashizume L, Maltz M. The effect of different formulations of chlorhexidine in reducing levels of mutans streptococci in the oral cavity: a systematic review of the literature. J Dent 2007; 35: 359-370.

27. Twetman S, Petersson L. Efficacy of a chlorhexidine and a chlorhexidine-fluoride varnish mixture to decrease interdental levels of mutans streptococci. Caries Res 1997; 31: 361-365.

28. Attin R, Tuna A, Attin T, Brunner E, Noack M. Efficacy of differently concentrated chlorhexidine varnishes in decreasing Mutans streptococci and lactobacilli counts. Arch Oral Biol 2003; 48: 503-509.

29. Reynolds E. Remineralization of enamel subsurface lesions by casein phosphopeptide-stabilized calcium phosphate solutions. J Dent Res 1997; 76: 1587-1595

30. Reynolds E. Anticariogenic complexes of amorphous calcium phosphate stabilized by casein phosphopeptides: a review. Spec Care Dent 1998; 18: 8-16.

31. GC Tooth Mousse webpage. www.gcasia.info/content_GC_Tooth_Mousse.html (accessed 23 June 2008).

32. Stiefel D, Truelove E, Chin M, Xhu X, Leroux B. Chlorhexidine swabbing applications under various conditions of use in preventive oral care for persons with disabilities. Spec Care Dent 1995; 15: 159-165.

33. Mackie I. Doctors must take the lead by prescribing sugar free medicines whenever possible. BMJ 1995; 311: 141-142.

34. Maguire A, Rugg-Gunn A, Butler T. Dental health of children taking antimicrobial and non-antimicrobial medication long term. Caries Res 1996; 30: 16-21.

35. Field E. Age and medication are significant risk factors for xerostomia in an English population attending general dental practice. Gerodontology 2001: 18: 21-24.

36. Walton A, Rutland R. Glyceryl trinitrate preparation causes caries and changes to denture base material. Br Dent J 1998; 185: 288-289.

37. Durrieu G, Llau M, Rascol D, Denard J, Rascol A,
Montastruc J. Parkinson's disease and weight loss: a study with anthropometric and nutritional status. Clin Autonomy Res 1992; 2: 153-157.

38. Hyland K, Fiske J, Matthews N. Nutritional and dental health management in Parkinson's disease. J Community Nurs Online 2000; 14(1). www.jcn. co.uk/journal.asp?MonthNum =01\&YearNum =200 O\&type $=$ search \& Article $I D=306$

39. Ahlborg B. Treatment cushions in the dental care of patients with disabilities. J Disabil Oral Health 2001; 2: 37-38.

40. Edgar W. Sugar substitutes, chewing gum and dental caries - a review. Br Dent J 1998; 184: 29-32.

41. Nordenram G, Ryd-Kjellen E, Ericsson K, Winblad $B$. Dental management of Alzheimer patients. A predictive test of dental cooperation in individualized treatment planning. Acta Odontol Scand 1997; 55: 148-154.

42. Department of Health. Care homes for older people. National minimum standards and the care homes regulations 2001. 3rd ed. London: The Stationery Office, 2003. www dh gov.uk/en/Publicationsandstatistics/Publications/PublicationsPolicyAndGuidance/DH_4005819

43. Almomani F, Brown C, Williams K. The effect of an oral health promotion program for people with psychiatric disabilities. J Psychiatr Rehabil 2006; 29: 274-281.

44. Whittle J, Sarll D, Grant A, Worthington H. The dental health of the elderly mentally ill: a carer's perspective. Br Dent J 1988; 164: 144-147.

45. Hilton C, Simons B. Dental surgery attendance amongst patients with moderately advanced dementia attending a day unit: a survey of carers' views. Br Dent J 2003; 195: 39-40.

46. Fiske J, Frenkel H, Griffiths J, Jones V. Guidelines for the development of local standards of oral health care for people with dementia. Gerodontology 2006; 23(Suppl 2): 5-32.

47. Fiske J, Weeks J. Oral care of people with disability: a qualitative exploration of the views of nursing staff. Gerodontology 1994; 11: 13-17.

48. Budtz-Jørgensen E, Mojon P, Rentsch A, Deslauriers N. Effects of an oral health program on the occurrence of oral candidosis in a long-term care facility. Community Dent Oral Epidemio/ 2000; 28: 141-149.

49. Simons D, Baker P, Jones B, Kidd E, Beighton D. An evaluation of an oral health training programme for carers of the elderly in residential homes. $\mathrm{Br}$ Dent J 2000; 188: 206-210.

50. Brady M, Furlanetto D, Hunter R, Lewin S, Milne V. Staff-led interventions for improving oral hygiene in patients following stroke. Cochrane Database Syst Rev 2006; 4: CD003864. DOI: 10.1002/14651858.CD003864.pub2.

51. Frenkel H. Behind the screens: care staff observations on delivery of oral health care in nursing homes. Gerodontology 1999; 16: 75-80.

52. Frenkel H, Harvey I, Newcome R. Oral health care among nursing home residents in Avon. Gerodontology 2000; 1: 33-38.

53. Frenkel $H_{1}$ Harvey I, Needs K. Oral health care education and its effect on caregivers' knowledge and attitudes: a randomised controlled trial. Com munity Dent Oral Epidemiol 2002; 30: 91-100.

54. Office of Public Sector Information. The Care Standards Act Chapter 14. London: The Stationery Office, 2000.

55. The Alzheimer's Society website. 2008. www. alzheimers.org.uk

56. Care Services Improvement Partnership. CSIP factsheet. Creative models of short breaks (respite care) for people with dementia. Leeds: CSIP, 2008. www.olderpeoplesmentalhealth.csip.org.uk/silo/ files/short-breaks-pdf.pdf

57. Department of Health. Putting people first: a shared vision and commitment to the transformation of adult social care. London: Department of Health, 2007. www.dh.gov.uk/en/Publicationsandstatistics/Publications/PublicationsPolicyAndGuidance/DH_081118

58. Department of Health. New ways of working for everyone: a best practice implementation guide. London: Department of Health, 2007. www.dh.gov. uk/en/Publicationsandstatistics/Publications/ 
PublicationsPolicyAndGuidance/DH_079102

59. Department of Health. Our NHS our future: NHS next stage review - interim report. London: Department of Health, 2007. www.dh.gov.uk/en/ Publicationsandstatistics/Publications/PublicationsPolicyAndGuidance/DH 079077

60. Department of Health. Meeting the challenges of oral health for older people: a strategic review. Gerodontology 2005; 22(Suppl 1): 3-48.

61. Smith M, Freeman R. Do healthcare professionals refer housebound people to dental services? Referral behaviours and characteristic factors. J Disabil Oral Health 2003; 4: 51-57.

62. Nunn J, Boyle C, Thompson S, Wilson K. Developing an undergraduate curriculum in special care dentistry. British Society for Disability and Oral Health, 2004. http://www.bsdh.org.uk/misc/ Teaching_doc_06july04.pdf

63. General Dental Council. The first five years - a framework for undergraduate dental education. London: GDC, 2002.

64. Federation Dentaire Internationale. Report of Working Group 11: oral health and the handicapped. In Epidemiology. London: Federation Dentaire Internationale, 1989.

65. Erridge P. Dentistry for the handicapped: a survey of current teaching. Br Dent J 1986: 161: 261-263.

66. Shanley D, Dowling P, Claffey N, Nattestad A. European convergence towards higher standards in dental education: the dental education thematic network project. Med Educ 2002; 36: 186-192.

67. Thompson S A, Griffiths J, Hunter M L, Jagger $R$, Korzun A, McLaughlin W. Development of an undergraduate curriculum in special care dentistry. J Disabil Oral Health 2001; 1: 71-77.

68. The Quality Assurance Agency for Higher Education. Academic standards - dentistry. Gloucester:
The Quality Assurance Agency for Higher Education, 2002. http://www.qaa.ac.uk/academicinfrastructure/benchmark/honours/Dentistry.pdf

69. Dougall A J, Griffiths J, Nunn J, Thompson S A. Symposium in undergraduate teaching in special care dentistry. Held at the 2004 Congress of the International Association for Disability and Oral Health, Calgary, Canada, 2004.

70. Boyle C. Teaching undergraduate special care dentistry. J Disabil Oral Health 2005; 6: 82-88.

71. Zoitopoulos L, Papadakis T, Tanna Y, Dunne S. Student evaluation of clinical outreach teaching in community special care dentistry. J Disabil Oral Health 2007: 8: 86-90.

72. General Dental Council. Developing the dental team: curricula frameworks for registrable qualifications for professionals complementary to dentistry. London: General Dental Council, 2004.

73. Oliver C, Nunn J. The accessibility of dental treatment to adults with physical disabilities in northeast England. Spec Care Dent 1996 16: 204-209

74. Griffiths J, Jones V, Leeman I et al. Oral health care for people with mental health problems: guidelines and recommendations. British Society for Disability and Oral Health, 2000. http://www.bsdh. org.uk/guidelines/mental.pdf

75. Fiske J, Griffiths J, Jamieson R, Manger D. Guidelines for oral health care for long-stay patients and residents. British Society for Disability and Oral Health, 2000. http://www.bsdh.org.uk/guidelines/ longstay.pdf

76. Fiske J, Lewis D. The development of standards for domiciliary dental care services: guidelines and recommendations. British Society for Disability and Oral Health, 2000. http://www.bsdh.org. uk/guidelines/domicil.pdf
77. Arnold C, Brookes V, Griffiths J, Maddock S, Theophilou S. Guidelines for oral health care for people with a physical disability. British Society for Disability and Oral Health, 2000. http://www.bsdh. org.uk/guidelines/physical.pdf

78. Griffiths J, Jones V, Leeman I, Lewis D, Patel $K$ Wilson K. Guidelines for the development of local standards of oral health care for dependent, dysphagic, critically and terminally ill patients. British Society for Disability and Oral Health, 2000. http://www.bsdh.org.uk/guidelines/depend.pdf

79. Clinical Effectiveness Committee, Faculty of Dental Surgery of the Royal College of Surgeons of England. Multi-disciplinary guidelines for the oral management of patients following oncology treatment. British Society for Disability and Oral Health, 2000. http://www.bsdh.org.uk/guidelines/ oncolradio.pdf

80. British Society for Disability and Oral Health/ Faculty of Dental Surgery of Royal College of Surgeons of England. Clinical guidelines and integrated care pathways for the oral health care of people with learning disabilities. British Society for Disability and Oral Health, 2001. http://www. bsdh.org.uk/guidelines/Dianatru.pdf

81. National Examining Board for Dental Nurses website. www.nebdn.org

82. Faculty of General Dental Practice (UK). List of accredited courses towards the FGDP(UK) Career Pathway. London: FGDP(UK), 2008. www.fgdp.org. uk/pdf/cp_qual.pdf

83. Burke F J, Crisp R J, McCord J F. Research in dental practice: a 'SWOT' analysis. Dent Update 2002; 29: 80-84, 86-87.

84. British Society for Disability and Oral Health. BSDH prizes webpage. http://www.bsdh.org.uk/annualprize.html (accessed 24 June 2008). 